\title{
What causes pneumonia in children who have had their jabs?
}

\author{
Gemma L Saint, Dan B Hawcutt, Paul S McNamara
}

Emergency department physicians and paediatricians frequently have to decide how best to manage community-acquired pneumonia (CAP). For a febrile child who has increased respiratory effort, oxygen requirement and a chest X-ray (CXR) consistent with lobar pneumonia, the decision to commence antibiotic therapy is straightforward. However, other patients may present more of a dilemma. What about children with respiratory symptoms but only a low-grade $\left(<38^{\circ} \mathrm{C}\right)$ fever? Or children whose respiratory symptoms are sufficient to require admission, but whose CXR is equivocal? Current British Thoracic Society (BTS) guidelines state all children with a clinical diagnosis of CAP should be given antibiotics. ${ }^{1}$ However, with increasing concern about antimicrobial resistance, consideration needs to be given to the likelihood of a bacterial cause.

The BTS guidelines also suggest that microbiological diagnosis, which could separate out viral and bacterial causes, should only be attempted in children with severe CAP needing paediatric intensive care, but not those with milder disease. ${ }^{1}$ However, these guidelines are 7 years old, and were based on studies that predate the inclusion of pneumococcal conjugate vaccines (PCV13, Pfizer) into many immunisation regimens. Similarly, multiplex polymerase chain reaction (PCR) was not as widely or as relatively cheaply available.

In this issue of Thorax, Bhuiyan et al assess the extent to which viruses and bacteria contribute to childhood CAP in Perth, Western Australia, where pneumococcal vaccination rates are over $90 \%$ and influenza vaccine is provided for preschool children over 6 months and high-risk older children. $^{2} 3$ In a case-control study, they recruited 230 children aged $<18$ years presenting to hospital with CAP concurrently with 230 healthy controls identified from outpatient and immunisation clinics. Nasopharyngeal swabs from both groups were tested for multiple viruses and bacteria. Crude ORs and multiple logistic regression were used to calculate relative

Institute in the Park, Alder Hey Children's Hospital, University of Liverpool, Liverpool, Merseyside, UK

Correspondence to Prof Paul S McNamara, Institute in the Park, Alder Hey Children's Hospital, University of Liverpool, Liverpool L69 3BX, UK;

mcnamp@liverpool.ac.uk frequency of detection and adjusted OR, respectively, for each respiratory pathogen for cases and controls.

Their finding that almost half childhood CAP in this population was attributable to respiratory viruses support other recent studies reporting an underestimation of viral causes of CAP by Rhedin et $a l^{4}$ and Jain et $a l^{5}$ in Sweden and USA, respectively. Similar recognition of the role of respiratory viruses in both pneumonia and sepsis in low-income and middle-income countries is also coming from the Bill \& Melinda Gates Foundation funded Pneumonia Etiology Research for Child Health $(\mathrm{PERCH})^{6}$ and Aetiology of Neonatal Infection in South Asia (ANISA) ${ }^{8}$ studies. In the present study, the authors show that respiratory syncytial virus (RSV) and human metapneumovirus (hMPV) were associated with $\sim 20 \%$ and $\sim 10 \%$ of CAP cases, respectively. They also show that rates of CAP were higher in those attending day care and in those who had significant comorbidities. To many paediatricians, these results will come as no surprise. However, it is noteworthy that the contribution of RSV and hMPV is not limited to infancy with these two viruses being the major cause of CAP in preschool children, particularly those between 1 and 3 years. This is important to know given the plethora of new RSV antivirals ${ }^{9-11}$ and potential vaccines ${ }^{12}$ coming through the therapeutic pipeline.

While these data suggest pathogenic roles for RSV and hMPV in CAP when detected in the upper respiratory tract, the same cannot be said for rhinovirus (RV). It is known that RV infection with different strains is common in early life and that RV RNA rarely persists beyond 30 days after RV infection. ${ }^{13}$ In this study, RV was detected more frequently than any other virus, but was as frequently detected in cases and controls. Further, speciation data showed similar RV A, B and C frequencies in both groups. In children attending hospital with respiratory symptoms, RV is commonly detected either with or without other pathogens by multiplex PCR in nasopharyngeal samples. These findings might make paediatricians less likely to attribute these symptoms and associated signs to RV in such cases.
These RV data contrast with those from children with acute wheeze and asthma in whom RV-A and C are a common cause of exacerbations. ${ }^{14} 15$ Should we take from this that RV causes asthma exacerbations but not CAP? Possibly, but with the caveat that our understanding of the role of RV in childhood respiratory disease is still evolving. ${ }^{16}$ In asthmatics, mutations in host genes are associated with enhanced $\mathrm{RV}-\mathrm{C}$ binding and increased progeny yields. ${ }^{17}$ It is possible that other, as yet unknown mutations predispose some individuals to RV lower respiratory tract symptoms or possibly secondary bacterial infection.

Over the last two decades, successful vaccination programmes against Streptococcus pneumoniae (SP) and Haemophilus influenzae (Hib) have decreased the mortality and incidence of bacterial CAP in the high-income countries. ${ }^{18}$ In this Perth cohort, bacteria were detected in the upper airways of $72 \%$ of cases and $80 \%$ controls but only Mycoplasma pneumoniae was associated with CAP in children of all ages. SP and Hib were found in over $25 \%$ of all samples and were as frequently found in samples from cases and controls. SP was found more frequently in cases of CAP in infancy but the number of cases and controls was small. Again, what do these results really mean? They confirm that SP and Hib are commonly found as commensals in the upper airways of healthy children. Perhaps more importantly, they show that nasopharyngeal sampling is likely to add little to our understanding of bacterial pneumonia aetiology in children. However, as the authors rightly mention, the lack of evidence of a contribution by bacteria to CAP in this population does not discount a potential role. This might be as a secondary bacterial infection or it could be as a contemporaneous coinfection with both virus and bacteria. It is interesting to note that $45 \%$ of cases had both viruses and bacteria detected compared with $24 \%$ of controls. It would have been interesting to know whether certain virus-bacteria combinations such as RSV and SP or Hib were more frequently found in cases.

Within this and other epidemiological studies, the diagnosis of CAP was made on radiographic findings and acute respiratory symptoms \pm fever. In many centres, a proportion of these children, such as those with non-specific CXR changes or respiratory symptoms without fever, may not have been labelled as having CAP. The broad diagnostic criteria employed here mean that some (especially the younger ones) conceivably could have had bronchiolitis or other viral induced symptoms 
for which a CAP diagnosis, and therefore, antibiotics would not normally be considered. This epidemiological study does not contain sufficient clinical information with which to examine this in more detail. Similarly, although some information is given about invasive pleural infections, there is no information about the relationship between pathogen, disease severity or outcomes, particularly whether children received antibiotic therapy based on their diagnosis of CAP.

Increasingly, in high-income countries, paediatricians are managing vaccinated children with respiratory disease with multiplex PCR results indicating a virus or bacterium is present in the upper airways. This study helps by confirming that RSV and hMPV are likely causes of CAP, particularly in younger children. The resonant questions for doctors include how certain can they be that a pathogen detected in the upper airway, even if it is RSV or hMPV, is causing lower airway disease, and should this knowledge direct treatment?

Correction notice This article has been corrected since it was published Online First. The article title was changed from "Contribution of respiratory viruses and bacteria to community-acquired pneumonia in highly vaccinated children: a casecontrol study".

Contributors All three authors have contributed to the writing of this manuscript.

Funding The authors have not declared a specific grant for this research from any funding agency in the public, commercial or not-for-profit sectors.

Competing interests None declared.

Patient consent Not required.
Provenance and peer review Commissioned; externally peer reviewed.

(C) Author(s) (or their employer(s)) 2019. No commercial re-use. See rights and permissions. Published by BMJ.

\section{A) Check for updates}

To cite Saint GL, Hawcutt DB, McNamara PS. Thorax 2019;74:211-212.

Accepted 10 December 2018

Published Online First 4 January 2019

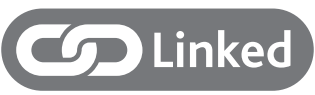

http://dx.doi.org/10.1136/thoraxjnl-2018-212096

Thorax 2019;74:211-212.

doi:10.1136/thoraxjnl-2018-212625

\section{REFERENCES}

1 Harris M, Clark J, Coote N, et al. British Thoracic Society guidelines for the management of community acquired pneumonia in children: update 2011. Thorax 2011;66(Suppl 2):ii1-23.

2 Bhuiyan MU, Snelling TL, West R, et al. Role of viral and bacterial pathogens in causing pneumonia among Western Australian children: a case-control study protocol. BMJ Open 2018:8:e020646.

3 Bhuiyan MU, Snelling TL, West R, et al. The contribution of viruses and bacteria to communityacquired pneumonia in vaccinated children: a casecontrol study. Thorax 2019;74:261-9.

4 Rhedin S, Lindstrand A, Hjelmgren A, et al. Respiratory viruses associated with community-acquired pneumonia in children: matched case-control study. Thorax 2015;70:847-53.

5 Jain S, Williams DJ, Arnold SR, et al. Communityacquired pneumonia requiring hospitalization among U.S. children. N Engl J Med 2015;372:835-45.

6 Deloria Knoll M, Fu W, Shi Q, et al. Bayesian estimation of pneumonia etiology: epidemiologic considerations and applications to the pneumonia etiology research for child health study. Clin Infect Dis 2017;64:S213-27.

7 Feikin DR, Fu W, Park DE, et al. Is higher viral load in the upper respiratory tract associated with severe pneumonia? findings from the PERCH study. Clin Infect Dis 2017:64:S337-6.

8 Saha SK, Schrag SJ, El Arifeen S, et al. Causes and incidence of community-acquired serious infections among young children in south Asia (ANISA): an observational cohort study. Lancet 2018;392:145-59.

9 DeVincenzo JP, McClure MW, Symons JA, et al. Activity of Oral ALS-008176 in a respiratory syncytial virus challenge study. N Eng/ J Med 2015;373:2048-58.

10 DeVincenzo JP, Whitley RJ, Mackman RL, et al. Oral GS 5806 activity in a respiratory syncytial virus challenge study. N Engl J Med 2014;371:711-22.

11 Stevens M, Rusch S, DeVincenzo J, et al. Antiviral Activity of Oral JNJ-53718678 in Healthy Adult Volunteers Challenged With Respiratory Syncytial Virus: A Placebo-Controlled Study. I Infect Dis 2018;218:748-56.

12 Blanco JCG, Boukhvalova MS, Morrison TG, et al. A multifaceted approach to RSV vaccination. Hum Vaccin Immunother 2018;14:1734-45.

13 Loeffelholz MJ, Trujillo R, Pyles RB, et al. Duration of rhinovirus shedding in the upper respiratory tract in the first year of life. Pediatrics 2014;134:1144-50.

14 Cox DW, Bizzintino J, Ferrari G, et al. Human rhinovirus species $C$ infection in young children with acute wheeze is associated with increased acute respiratory hospital admissions. Am J Respir Crit Care Med 2013;188:1358-64.

15 Fawkner-Corbett DW, Khoo SK, Duarte CM, et al. Rhinovirus- $C$ detection in children presenting with acute respiratory infection to hospital in Brazil. J Med Virol 2016;88:58-63.

16 Bochkov YA, Gern JE. Rhinoviruses and their receptors: implications for allergic disease. Curr Allergy Asthma Rep 2016;16:30.

17 Bochkov YA, Watters K, Ashraf S, et al. Cadherinrelated family member 3 , a childhood asthma susceptibility gene product, mediates rhinovirus $C$ binding and replication. Proc Natl Acad Sci U S A 2015:112:5485-90.

18 Active Bacterial Core Surveillance (ABCs). Surveillance Reports. 2018 https://www.cdc.gov/abcs/reportsfindings/surv-reports.html. 